\title{
aniki
}

Revista Portuguesa da Imagem em Movimento

Portuguese Journal of the Moving Image

\section{Técnica do Cinema e Produção de Sentido}

\section{Liliana Rosa}

Escola Superior Artística do Porto/ Escola Superior de Tecnologia de Abrantes do Instituto Politécnico de Tomar

lcvrosa@gmail.com

https://orcid.org/0000-0002-3447-9262

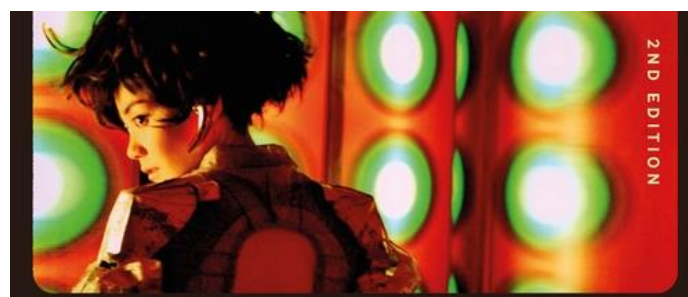

\section{AN INTRODUCTION TO}

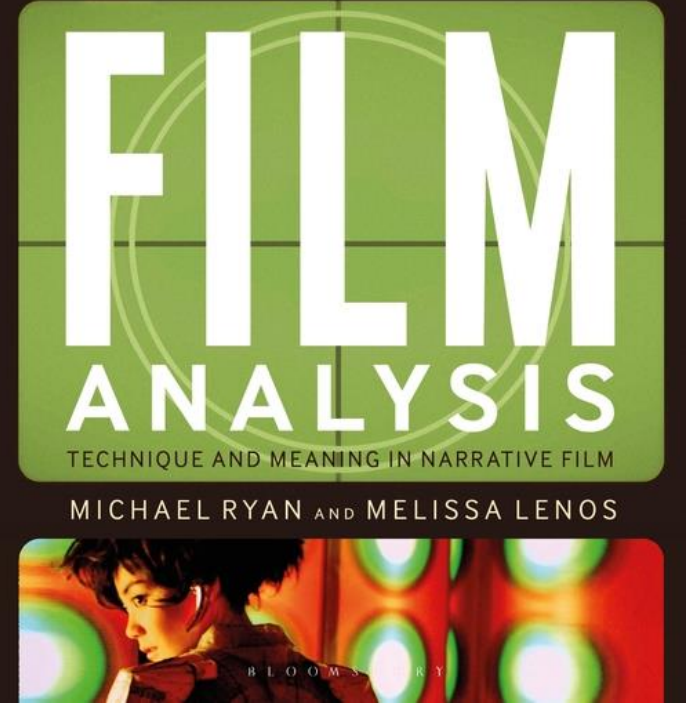

Ryan, Michael, e Lenos, Melissa. 2020. An Introduction to Film Analysis: Technique and meaning in narrative film. New York: Bloomsbury Academic, 276 pp. ISBN 9781501318542.

O que é a análise de filmes? Como podemos analisar um filme? Estas são algumas perguntas que colocamos quando queremos analisar um filme e, por vezes, não sabemos muito bem como começar. Na tentativa de responder a estas e outras questões, Michael Ryan e Melissa Lenos fornecem uma introdução à análise de filmes através de uma linguagem simples e acessível aos alunos, aos professores, aos profissionais da área 
do cinema e a todos os curiosos que se interessam por cinema e, em particular, pela análise fílmica.

Nesta obra, Ryan e Lenos ensinam a analisar a técnica do filme no processo de produção de sentido, avançando, de seguida, para cincoanálises fílmicas. Finalmente, os autores adentram-se numa análise crítica de um corpus de filmes a partir das variantes histórica, psicológica, ideológica, de género, 'raça', política, pós-estruturalista e científica.

Em termos estruturais, o livro desenvolve-se em três partes. A primeira parte, com o título, "Technique and Meaning", começa por falar da composição, em particular o contributo da composição simétrica e assimétrica na produção de sentido. Segue-se uma investida sobre o trabalho de câmara, nomeadamente a posição da câmara em relação ao que é filmado - a variação que se estabelece entre planos mais próximos e planos mais afastados, a escolha entre ângulos picados ou contrapicados, os movimentos de câmara através dos quais o realizador procura situar ou alinhar os espectadores de determinadas maneiras contribuem decisivamente para a construção da história e a produção de sentido. Ryan e Lenos exploram também o conceito de "edição" como a arte de seleção e combinação de planos, imagens e cenas que contribuem para a comunicação de ideias. Segundo os autores, semelhança, paralelismo, contraste e ironia são alguns princípios que podem guiar a edição de um filme: "Editing often serves a polemical or ideological purpose because it allows filmmakers to shape the audience's perceptions by combining pieces of film into sequences that determine how the audience sees a situation and the players in it" ( $p$. 78). No capítulo dedicado à cor, à luz e ao som, os autores salientam o papel importantíssimo da cor no cinema, em particular, na criação dos efeitos emocionais e chamam a atenção para a existência de mais do que um significado para cada cor. Os níveis de saturação das imagens também têm um papel fundamental no âmbito dos efeitos semânticos. O som é outro elemento essencial para a construção das personagens, produção dos efeitos emocionais e criação de sentido. Finalmente, os autores adentram-se nas particularidades da iluminação e na forma como pode ser utilizada na criação de efeitos emocionais.

A segunda parte do livro, com o título, “Close Viewings”, é constituída por cinco capítulos que se dedicam à análise do seguinte corpus de filmes: Tengoku to jigoku (Akira Kurosawa, 1963), The Shining (Stanley Kubrick, 1980), Disponível para Amar / Fayeungninwah (Kar-Wai 
Wong), Sem Eira nem Beira / Sans toit ni loi (Agnès Varda, 1985) e $O$ Primeiro Encontro / Arrival (Denis Villeneuve, 2016). Chamo a atenção para a pertinência, a originalidade e a clareza destas análises que têm como ponto de partida as especificidades da técnica do cinema no processo de produção de sentido, abordadas na primeira parte do livro. Deste conjunto de análises, gostaria de destacar a análise do filme Tengoku to jigoku, que explora a composição para mostrar o conflito entre os valores da cultura tradicional japonesa e a adoção de certos valores capitalistas ocidentais por parte de algumas personagens, nomeadamente o protagonista, Kingo Gondo (Toshirô Mifune). Apesar da encruzilhada moral e de alguma resiliência, Gondo decide-se pela cultura tradicional japonesa, sacrificando, assim, a possibilidade de sucesso capitalista.

Na análise do filme The Shining, Ryan e Lenos fazem uma breve distinção entre conservadores e liberais e analisam a personagem principal, Jack (Jack Nicholson), que utiliza a violência contra a esposa e o filho para discipliná-los, ou seja, revelando um conservadorismo tradicional no modo de olhar as relações familiares. Segundo Ryan e Lenos, o filme centra-se no conflito entre civilidade e animalidade, ou seja, entre o nosso lado mais humano, civilizado, e os nossos impulsos mais animais e violentos. Este conflito entre a civilidade e a animalidade é analisado ao nível da composição, iluminação, mise-enscène, caraterização das personagens e cor. Os autores concluem, "The film, with its red, white, and blue palette, is about how America is haunted by its history of violence against indigenous people, enslaved Africans, women and children, and working-class people" (p. 170).

Finalmente, a terceira parte do livro, com o título, "Critical Analysis", examina um corpus de filmes a partir de diferentes dimensões: uma dimensão histórica, em Orgia Dourada / Gold Diggers of 1933 (Mervyn LeRoy, 1933), psicológica, em O Silêncio dos Inocentes / The Silence of the Lambs (Jonathan Demme, 1991), ideológica, em Uma Mulher de Sucesso / Working Girl (Mike Nichols, 1988), de género, em Alma em Suplício / Mildred Pierce (Michael Curtiz), de 'raça', em Um Dia de Raiva / Falling Down (Joel Schumacher, 1993) e Foge / Get Out (Jordan Peele, 2017), política, em Apocalypse Now (Francis Ford Coppola, 1979), pósestruturalista, em $O$ Padrinho / The Godfather (Francis Ford Coppola, 1972) e, finalmente, uma dimensão científica, em A Desaparecida / The Searchers (John Ford, 1956). Deste conjunto de análises sobressai a análise do filme Um Dia de Raiva com base na variante racial. Os 
autores defendem que muito do racismo contemporâneo nos Estados Unidos da América está associado à classe económica, na medida em que é mais simples culpar grupos étnicos pelo sofrimento económico do que o sistema económico que distribui riqueza de forma desigual, colocando, assim, uma enorme pressão sobre a vida das pessoas mais pobres. Este filme dramatiza as questões raciais contemporâneas nos Estados Unidos da América do ponto de vista de um homem branco americano conservador, D-Fens (Michael Douglas), que perde o emprego e a família e, consequentemente, sente ressentimento contra os novos grupos de imigrantes (por exemplo, castigando um ásioamericano por não ser suficientemente americano e entrando numa luta com um grupo de homens latinos).

Outra análise fílmica a destacar é a abordagem política ao filme Apocalypse Now. Segundo Ryan e Lenos, o filme funciona como um eco do individualismo económico da filosofia política conservadora que dominou o discurso público americano no final da década de 70. A Ásia é retratada como perpetuadora do barbarismo primitivo, a religião budista é associada ao sacrifício de sangue, enquanto a "missão" dos soldados heróicos americanos é vinculada à narrativa da história de Cristo. O filme mostra-nos um retrato da Guerra que foi perdida pelos liberais: "What is needed, the filmmakers argue, is strong visionary leadership by a conservative individualistic that transcends bureaucratic procedures, legal rules, civilian democratic protest, and the restraints of moral conscience" (p. 245).

An Introduction to Film Analysis: Technique and meaning in narrative film fornece, como vimos, várias ferramentas para a análise de filmes e apresenta um conjunto diverso de análises fílmicas. Esta diversidade é um ponto forte, na medida em que os filmes analisados são oriundos de vários perímetros geográficos, nomeadamente América, Europa e Ásia. Contudo, os autores podiam ter explorado ainda mais essa diversidade, se não tivessem centrado grande parte das análises em filmes americanos. Apesar desta reserva, muitos filmes analisados são amplamente conhecidos e essa particularidade poderá traduzir-se em vantagem. Outro ponto forte do livro assenta nas sugestões de exercícios de análise fílmica no final de cada um dos capítulos que compõem a primeira parte. Estas propostas de análise são um excelente complemento para testarmos as ferramentas de análise disponibilizadas pelos autores. 
Para terminar, não posso deixar de referir que a análise de filmes está longe de ser um novo campo na esfera dos estudos fílmicos, para o qual têm contribuído inúmeros autores, tais como Aumont (2009), Aumont e Marie (2009), Gardies (2015) e Martin (2005). Todavia, apesar deste vasto legado teórico, a análise fílmica contínua a ser um campo frutífero no interior dos estudos fílmicos. A singularidade de An Introduction to Film Analysis: Technique and meaning in narrative film reside, sobretudo, na forma como explora o significado explícito e intencional nos filmes, por um lado, e a grande variedade de significados que são delineados pelas dimensões económicas, políticas, históricas e relações de género, por outro lado. Sem dúvida que o grande contributo desta introdução à análise de filmes assenta na forma como Ryan e Lenos analisam a técnica utilizada por alguns cineastas no processo de construção de sentido. Se o grande plano, o plano longo, a iluminação, etc., são utilizados para criar sentidos que podem variar de acordo com as diferentes instâncias em que ocorre (por exemplo, um grande plano pode sugerir intimidade emocional ou medo), então os autores investigam essas técnicas com o objetivo de determinar quais são esses sentidos.

\section{Referências}

Aumont, Jacques. 2009. A Imagem. Lisboa: Edições Texto \& Grafia.

Aumont, Jacques, \& Marie, Michel. 2009. A Análise do Filme. Lisboa: Edições Texto \& Grafia.

Gardies, René, ed. 2015. Compreender o Cinema e as Imagens. Lisboa: Edições Texto \& Grafia.

Martin, Marcel. 2005. A Linguagem Cinematográfica. Lisboa: Dinalivro. 